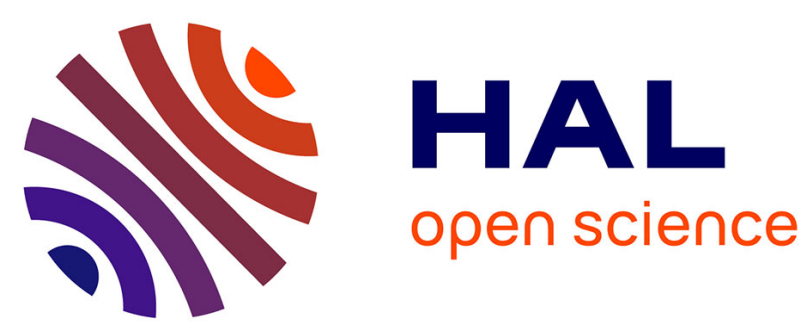

\title{
Toxicity of boehmite nanoparticles: impact of the ultrafine fraction and of the agglomerates size on cytotoxicity and pro-inflammatory response
}

Valérie Forest, Mélanie Pailleux, Jérémie Pourchez, Delphine Boudard, Maura Tomatis, Bice Fubini, Mohamed Sennour, Jean-François Hochepied, Philippe Grosseau, Michèle Cottier

\section{To cite this version:}

Valérie Forest, Mélanie Pailleux, Jérémie Pourchez, Delphine Boudard, Maura Tomatis, et al.. Toxicity of boehmite nanoparticles: impact of the ultrafine fraction and of the agglomerates size on cytotoxicity and pro-inflammatory response. Inhalation Toxicology, 2014, 26 (9), pp.545-553. 10.3109/08958378.2014.925993 . hal-01020274

\section{HAL Id: hal-01020274 https://hal.science/hal-01020274}

Submitted on 19 Sep 2014

HAL is a multi-disciplinary open access archive for the deposit and dissemination of scientific research documents, whether they are published or not. The documents may come from teaching and research institutions in France or abroad, or from public or private research centers.
L'archive ouverte pluridisciplinaire HAL, est destinée au dépôt et à la diffusion de documents scientifiques de niveau recherche, publiés ou non, émanant des établissements d'enseignement et de recherche français ou étrangers, des laboratoires publics ou privés. 
Toxicity of boehmite nanoparticles: impact of the ultrafine fraction and of the agglomerates size on cytotoxicity and pro-inflammatory response.

Valérie Forest ${ }^{\mathrm{a}, \mathrm{b}, \mathrm{c}}$, Mélanie Pailleux ${ }^{\mathrm{a}, \mathrm{c}, \mathrm{d}}$, Jérémie Pourchez ${ }^{\mathrm{a}, \mathrm{b}, \mathrm{c}}$, Delphine Boudard ${ }^{\mathrm{a}, \mathrm{c}, \mathrm{e}, \mathrm{f,g}}$, Maura Tomatis $^{\mathrm{h}}$, Bice Fubini ${ }^{\mathrm{h}}$, Mohamed Sennour ${ }^{\mathrm{i}}$, Jean-François Hochepied ${ }^{\mathrm{i}, \mathrm{j}}$, Philippe Grosseau $^{\mathrm{d}}$, Michèle Cottier ${ }^{\mathrm{a}, \mathrm{c}, \mathrm{e}, \mathrm{f}, \mathrm{g}}$.

${ }^{a}$ LINA, EA 4624, 42023 Saint-Etienne, France

${ }^{\mathrm{b}}$ Ecole Nationale Supérieure des Mines de Saint-Etienne, CIS, 42023 Saint-Etienne, France

${ }^{\mathrm{c}}$ SFR IFRESIS, 42023 Saint-Etienne, France

${ }^{\mathrm{d}}$ Ecole Nationale Supérieure des Mines de Saint-Etienne, SPIN, CNRS:UMR5307, LGF, 42023 Saint-Etienne, France

${ }^{\mathrm{e}}$ Université de Lyon, 42023 Saint-Etienne, France

${ }^{\mathrm{f}}$ Université Jean Monnet, Faculté de Médecine, 42023 Saint-Etienne, France

${ }^{\mathrm{g}}$ CHU de Saint-Etienne, 42055 Saint-Etienne, France

${ }^{\text {h }}$ Dipartimento di Chimica and G. Scansetti' Interdepartmental Center for Studies on Asbestos and other Toxic Particulates, Università di Torino, Torino, Italy

${ }^{\mathrm{i}}$ MINES ParisTech, Centre des Matériaux, CNRS UMR 7633, 91003 Evry Cedex, France

${ }^{\mathrm{j}}$ ENSTA UCP/SCPI, 91762 Palaiseau cedex, France

Corresponding author and full contact information: Valérie FOREST, Centre Ingénierie et Santé, École Nationale Supérieure des Mines de Saint-Etienne, 158 cours Fauriel, CS 62362, 42023 SaintEtienne cedex 2, France. vforest@emse.fr. Tel: (+33) 4774997 76. Fax. (+33) 477499694.

Running title: Nanoparticles agglomeration and toxicity. 


\section{ABSTRACT}

Boehmite $(\gamma-\mathrm{AlOOH})$ nanoparticles (NPs) are used in a wide range of industrial applications. However, little is known about their potential toxicity. This study aimed at a better understanding of the relationship between the physico-chemical properties of these NPs and their in vitro biological activity. After an extensive physico-chemical characterization, the cytotoxicity, pro-inflammatory response and oxidative stress induced by a bulk industrial powder and its ultrafine fraction were assessed using RAW264.7 macrophages. Whereas the bulk powder did not trigger a significant biological activity, pro-inflammatory response was highly enhanced with the ultrafine fraction. This observation was confirmed with boehmite NPs synthesized at the laboratory scale, with well-defined and tightly controlled physicochemical features: toxicity was increased when NPs were dispersed. In conclusion, the agglomerates size of boehmite NPs has a major impact on their toxicity, highlighting the need to study not only raw industrial powders containing NPs but also the ultrafine fractions representative of respirable particles.

Key-words: boehmite nanoparticles, manufactured nanopowders, ultrafine fraction, toxicity, agglomerate size. 


\section{INTRODUCTION}

Boehmite $(\gamma-\mathrm{AlOOH})$ a component of the aluminum (Al) ore bauxite is an aluminum oxide hydroxide $(\mathrm{AlOOH})$ mineral. Nanosized $\gamma$ - $\mathrm{AlOOH}$ particles are used in a wide range of industrial applications and in many commercial products such as abrasive materials, catalysts, substrates for electronic circuits, refractory materials, ceramics, flame retardant in plastics... (Pauluhn 2009a). Moreover, boehmite nanoparticles can be used as adjuvants in vaccines (Wang and Singh 2011) and future applications in nanomedicine are expected. Growing use of this nanomaterial results in increasing risks of exposure, first at the workplace and the general population of final products users. Some toxicological evaluations have already been carried out but the potential toxicity of $\gamma$ - $\mathrm{AlOOH}$ nanoparticles (NPs) is not yet completely characterized.

In vitro experiments using the RAW 264.7 (murine macrophages) and A549 (human lung cancer) cell lines have shown that $\gamma$-AlOOH NPs can induce pro-inflammatory response and cytotoxicity (Kuhlbusch et al. 2009). Studies on macrophagic myofasciitis, an inflammatory myopathy related to aluminum hydroxide-containing vaccines, have shown the presence of boehmite intracytoplasmic inclusions in macrophages of the lesions. The etiology of this myopathy is still unknown but seems related to the long-term persistence of $\mathrm{AlOOH}$, resulting in local immune reaction. Although $\mathrm{Al}$ is a simple trivalent cation incapable of redox changes, an implication of oxidative stress in this pathology was not excluded (Bonnefont et al. 2004). It has been hypothesized that $\mathrm{Al}$ ions facilitate $\mathrm{Fe}(\mathrm{II})$ reaction with hydrogen peroxide, generating hydroxyl radicals (Crisponi et al. 2012). Finally, in vivo studies (Pauluhn 2009a; Pauluhn 2009b; Pauluhn 2011) have suggested that micrometric boehmite agglomerates composed of nanosized primary particles induced a pulmonary toxicity dependent on the agglomerate sizes. These studies were conducted in rats exposed to two types of $\gamma$-AlOOH powders consisting of primary particles of 10 and $40 \mathrm{~nm}$ respectively. Animals were nose- 
only exposed to different doses and followed up during three months. The respective mass median aerodynamic diameter (MMAD) of agglomerated particles in inhalation chambers was 1.7 and $0.6 \mu \mathrm{m}$. At serial sacrifices, pulmonary toxicity was characterized by bronchoalveolar lavage and histopathology. This latter revealed alveolar macrophages with enlarged and foamy appearance, increased epithelial cells, inflammatory cells, and focal septal thickening. The determination of $\mathrm{Al}$ in lung tissue showed that the cumulative lung dose was higher following exposure to $\gamma$-AlOOH-40 nm/MMAD-0.6 $\mu$ m than to $\gamma$-AlOOH-10 $\mathrm{nm} / \mathrm{MMAD}-1.7 \mu \mathrm{m}$, despite identical exposure concentrations and was associated with an increased pulmonary inflammatory response. The authors concluded that the pulmonary toxicity of nanosized, agglomerated $\gamma$-AlOOH particles was determined by the size of agglomerated rather than primary particles, suggesting that the agglomeration state of NPs plays a key role in boehmite toxicity. Taken together, these results strongly argue for the fact that $\gamma$-AlOOH NPs cannot be considered as totally innocuous and their potential impact on occupational health should be further analyzed.

It has been clearly demonstrated that the physico-chemical features of NPs have a direct impact on their biological activity (Boczkowski and Hoet 2010; Fubini et al. 2010; Jiang et al. 2009) and therefore they need to be taken into account in any nanotoxicology study. Indeed, physico-chemical properties are the clues for understanding molecular mechanisms of toxicity and, consequently, for a safe production of engineered nanomaterials. Parameters such as shape, chemical composition, specific surface area, primary particle size, size distribution of the particles, agglomeration state, surface charge and so on need to be thoroughly assessed before any in vivo or in vitro biological test as they are all relevant to toxicity studies (Fubini et al. 2010; Murdock et al. 2008). Among them, the agglomeration state of NPs begins to be considered as a crucial parameter in the toxicity of NPs as attested by recent studies (Magdolenova et al. 2012; Noël et al. 2012). For instance, Noël et al. compared in an in vivo 
model (rats) the relative pulmonary toxicity induced by aerosolized nano- $\mathrm{TiO}_{2}$ showing two different agglomeration states: small $(<100 \mathrm{~nm})$ and large $(>100 \mathrm{~nm})$ agglomerates. They demonstrated that biological response to $\mathrm{TiO}_{2}$ NPs depended not solely on the dimension of the NPs but also on the dimension of the nanoparticle agglomerates. It should also be kept in mind that bulk nanopowders can exhibit a toxicity different from that of their ultrafine, respirable fraction. During the handling and transport processes of powder materials dust emissions can occur and can potentially cause adverse health effects on workers. This phenomenon referred to as "dustiness" represents an important exposure determinant and is therefore crucial for industrial hygienists for risk assessment and control in an occupational health context (Schneider and Jensen 2009; Tsai et al. 2009).

The aim of the present study was to extend our understanding of the relationship between the physico-chemical properties of $\gamma$-AlOOH NPs (especially the agglomeration state) and their potential in vitro toxicity. After an extensive physico-chemical characterization, surface reactivity towards free radical generation $\left(\mathrm{HO} \bullet\right.$ and $\left.\mathrm{COO}^{\bullet^{-}}\right)$in cell-free medium and biological activities on RAW 264.7 macrophage cell line have been investigated for an industrial $\gamma-\mathrm{AlOOH}$ nanopowder and its respirable fraction (ultrafine fraction). The biological activities were assessed in terms of cytotoxicity (Lactate DeHydrogenase (LDH) release), proinflammatory effect (TNF $\alpha$ production) and oxidative stress induction (reactive oxygen species generation). As the dustiness property of a powder can be determined by a broad range of mechanisms including those that affect agglomeration and de-agglomeration (Schneider and Jensen 2009), the influence of the agglomerate size was assessed using $\gamma$ AlOOH NPs produced by hydrothermal synthesis at the laboratory scale. The main advantage of this way of synthesis is to obtain NPs of well-defined and perfectly controlled physicochemical features. And as reported by Schrurs and Lison (2009) model samples are very useful to answer basic mechanistic questions on biological reactivity. This is why a combined 
approach between the study of manufactured NPs and lab synthesized model samples was adopted in this study. Biological activity was evaluated before and after dispersion of the particles. 


\section{MATERIAL AND METHODS}

\subsection{Boehmite nanoparticles}

\subsubsection{Nanoparticles sources}

Two kinds of NPs were used in this study:

- Manufactured NPs: boehmite nanopowder was purchased from industry.

- Model NPs: lab synthesized $\gamma-\mathrm{AlOOH}$ NPs were prepared by Hydrothermal Synthesis (which will be referred to as HS $\gamma$-AlOOH NPs). Al nitrate and sodium hydroxide were mixed at $\mathrm{pH} 9$ to precipitate an amorphous $\mathrm{Al}$ hydroxide. This suspension was subsequently heated to $180^{\circ} \mathrm{C}$ in an autoclave during 45 min to crystallize boehmite NPs. After this hydrothermal treatment, particles were centrifuged and washed several times with distilled water, then freeze-dried.

\subsubsection{Ultrafine fraction recovery of manufactured nanopowder}

The industrial $\gamma$-AlOOH powders consisting of primary nanosized particles, show a wide particles size distribution. To study the influence of the agglomeration state, the first step was therefore to remove larger particles, keeping only the fine fractions. To that purpose, boehmite powders (10 mg) were elutriated: powders were aerosolized (fluidized in a gas), and were first selected through a cyclone which cut-off is set at $800 \mathrm{~nm}$ (flow rate of 10L.min ${ }^{-1}$ ). After this first selection, particles went through an electrical low pressure impactor (ELPI, Dekati) to recover the finest fractions which will be referred to as ultrafine fractions. The experimental setting is illustrated in Figure 1.

\subsubsection{Dispersion of nanoparticles produced by hydrothermal synthesis}

Similarly to study the influence of the agglomeration state of the lab synthesized $\gamma$-AlOOH NPs, HS nanopowder was dispersed in water, using ultrasound (300W) for 1 min. After dilution in cell culture medium, NPs were vortexed. 
The same tests for physico-chemical characterization and biological assays were performed on industrial and lab synthesized $\gamma$-AlOOH NPs (raw industrial boehmite and its ultrafine fraction, HS and dispersed HS nanopowders respectively).

\subsection{Boehmite nanopowders characterization}

\subsubsection{Morphology}

The particles morphology was assessed by electron microscopy in the scanning electron microscopy (SEM) mode in a field-emission scanning electron microscope (JEOL JSM6500F). For transmission electron microscopy (TEM) observations, images were acquired with a transmission electron microscope (MET TECNAI F20ST, FEI).

\subsubsection{Particle size, size distribution and zeta potential}

Suspensions of $100 \mathrm{mg} / \mathrm{L} \gamma-\mathrm{AlOOH}$ were prepared diluting nanopowder either in water or in complemented Dulbecco's modified Eagle's medium (DMEM). Particle size, size distribution, surface charge (zeta potential) and isoelectric point were determined using dynamic light scattering (DLS, ZetaSizer nano S, Malvern Instrument) and laser granulometry (Malvern, Mastersizer 2000).

\subsubsection{Specific surface area and density}

The specific surface area (SSA, $\mathrm{m}^{2} / \mathrm{g}$ ) was determined by $\mathrm{N}_{2}$ adsorption at $77 \mathrm{~K}$ after outgassing for $2 \mathrm{~h}$ at $200^{\circ} \mathrm{C}$ (Micromeritics ASAP 2000), using the Brunauer-Emmet-Teller (BET) method. The density $\left(\rho, \mathrm{g} / \mathrm{cm}^{3}\right)$ was determined using a gas pycnometer (Micrometrics AccuPyc 1330) working under a helium atmosphere. Results are expressed as means of 10 successive measurements on the same sample. Particle diameter (BET size, $\mu \mathrm{m}$ ) was calculated as BET size $=6,000 /(\rho *$ SSA $)$.

\subsubsection{Chemical analysis and surface composition}


The chemical analysis and the impurities were determined by inductively coupled plasma spectroscopy (ICP, Jobin-Yvon Activa). The mineralization consisted in suspending $250 \mathrm{mg}$ of powder in $1 \mathrm{~mL}$ nitric acid and $3 \mathrm{~mL}$ hydrochloric acid, the mix was agitated and heated for $1 \mathrm{~h}$ at $60^{\circ} \mathrm{C}$. X-ray diffraction (XRD) experiments were performed at room temperature to identify the different crystalline phases (Siemens D5000) with a semi-quantitative analysis by means of Rietveld method (Siroquant V2.5 software). The crystallite size was calculated from the diffractograms obtained using the Scherrer relation (Topaz-4P software). The surface composition was analyzed through X-ray photoelectron spectroscopy (XPS, Thermo VG Thetaprobe).

\subsection{Surface reactivity related to the oxidative stress}

Electron paramagnetic resonance (EPR) using the spin-trapping technique (Fubini et al. 1995) was used to evaluate $\gamma$-AlOOH NPs potential to generate free radicals $\left(\mathrm{HO} \bullet, \mathrm{COO}^{-}\right)$in aqueous suspensions. Each nanoparticle powder was suspended in a buffered solution $(0.5 \mathrm{M}$ potassium phosphate buffer, $\mathrm{pH} 7.4$ ) containing $0.15 \mathrm{M}$ of DMPO (5-5'-dimethyl-1-pirrolineNoxide) as spin trapping agent. The reaction was started by adding the target molecule respectively hydrogen peroxide solution (1.0M) and sodium formate (1.0M). The radical yield was progressively measured in a $50 \mu \mathrm{l}$ aliquot of the suspension up to one hour by EPR spectroscopy (Miniscope 100 EPR spectrometer, Magnettech). The instrument settings were as follows: microwave power $10 \mathrm{~mW}$; modulation $1000 \mathrm{mG}$; scan range $120 \mathrm{G}$; centre of field approximately 3345 G. The use of internal standard (Mn) enabled radical activity quantification. Each experiment was repeated three times.

\subsection{In vitro biological activity assessment}

\subsubsection{Cell culture}


The RAW 264.7 cell line was provided by ATCC Cell Biology Collection (Promochem LGC) and was derived from murine peritoneal macrophages transformed by the AMLV virus (Abelson Murine Leukemia Virus). Cells were cultured in DMEM medium (Dulbecco's Modified Eagle's Medium, Gibco) complemented with 10\% fetal calf serum (FCS, Gibco), $1 \%$ penicillin-streptomycin (penicillin 10000 units $/ \mathrm{mL}$, streptomycin $10 \mathrm{mg} / \mathrm{mL}$, Sigma) and incubated at $37^{\circ} \mathrm{C}$ under a $5 \%$ carbon dioxide humidified atmosphere.

\subsubsection{Toxicity assessment}

For each experiment, cells were prepared in 96-well plates $(100,000$ cells/well for TNF $\alpha$ and LDH assays, and 300,000 cells/well for ROS and $\mathrm{H}_{2} \mathrm{O}_{2}$ measurements) in $25 \mu \mathrm{L}$ of complete DMEM as previously described (Leclerc et al. 2010). $\gamma$-AlOOH NPs diluted in a volume of 75 $\mu \mathrm{L}$ of DMEM were added to the culture and incubated for $90 \mathrm{~min}$ or $24 \mathrm{~h}$ at $37^{\circ} \mathrm{C}$ in a $5 \% \mathrm{CO}_{2}$ atmosphere. Four $\gamma$-AlOOH NPs concentrations $(15,30,60$, and $120 \mu \mathrm{g} / \mathrm{ml})$ were tested. For each test a negative control was performed incubating cells alone, a positive control known for its toxicity: DQ12 quartz (Bruch et al., 2004; Fubini et al., 2004) was also included.

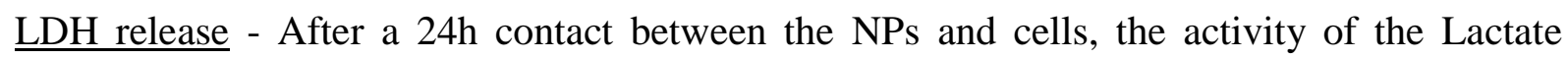
Dehydrogenase $(\mathrm{LDH})$ released from cells with damaged membranes was assessed using the CytoTox-ONE $^{\mathrm{TM}}$ Homogeneous Membrane Integrity Assay (Promega) according to the manufacturer's instructions. Detection was performed with a fluorometer (Fluoroskan Ascent, Thermolabsystems), using excitation/emission wavelengths at 530/590 $\mathrm{nm}$. The activity of the released LDH was reported in comparison to that of total cellular LDH (measured after the lysis of control cells) and was expressed as a percentage of the control.

Pro-inflammatory TNF- $\alpha$ response - After a $24 \mathrm{~h}$ incubation with NPs, the TNF $\alpha$ production was assessed in the culture supernatant by a commercial enzyme-linked immunosorbent assay (ELISA) kit (Quantikine ${ }^{\circledR}$ Mouse TNF $\alpha$ Immunoassay, R\&D Systems) according to the manufacturer's instructions. The optical density of each well was determined using a 
microplate reader (Multiskan RC, Thermolabsystems) set at $450 \mathrm{~nm}$. A standard curve was established and results were expressed in picograms of TNF $\alpha$ per milliliter of supernatant.

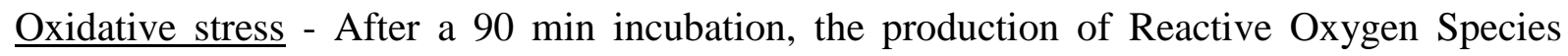
(ROS) was assessed using the OxiSelect ${ }^{\mathrm{TM}}$ ROS Assay Kit (Euromedex). The assay uses the conversion of a nonfluorescent substrate, $2^{\prime}, 7^{\prime}$-dichlorodihydrofluorescin diacetate that can easily diffuse through cell membranes and be converted into a fluorogenic molecule $2^{\prime}, 7^{\prime}-$ dichlorodihydrofluorescein (DCF) in presence of ROS and which fluorescent intensity is proportional to total ROS level. DCF production was detected using a Fluoroskan Ascent fluorometer (Thermolabsystems) using excitation and emission wavelengths of 480 and 530 $\mathrm{nm}$, respectively, results were expressed as nmol of ROS produced. Specific hydrogen peroxide $\left(\mathrm{H}_{2} \mathrm{O}_{2}\right)$ production was also assessed: after incubation, the cells were stimulated to release the $\mathrm{H}_{2} \mathrm{O}_{2}$ produced by addition of $100 \mathrm{ng} / \mathrm{ml}$ phorbol-12-myristate-13-acetate (Sigma). The release of $\mathrm{H}_{2} \mathrm{O}_{2}$ was measured as described by De la Harpe and Nathan (1985). Briefly, Krebs-Ringer phosphate glucose (KRPG) buffer containing a mixture of scopoletin $(30 \mu \mathrm{M})$, NaN3 (1 mM), and horseradish peroxidase (1 unit pupurogallin/ml HPO) was added to the cells. The horseradish peroxidase catalyzed the oxidation of the fluorescent scopoletin, which was measured over a period of 90 min (Fluoroskan Ascent, Thermolabsystems) using excitation/emission wavelengths at 355/460 nm. Results first expressed as arbitrary units of the fluorescence were converted in nmol of produced $\mathrm{H}_{2} \mathrm{O}_{2}$.

\subsection{Statistical analysis}

For each test, three independent experiments were carried out, results were expressed as means \pm standard deviation. Analysis and graphics were performed using Prism 5.0 software (GraphPad, San Diego, CA, USA). Significance was established with ANOVA test $(\mathrm{p}<0.05)$. 


\section{RESULTS}

\subsection{Physico-chemical characterization and surface reactivity evaluation}

\subsubsection{Study of manufactured aluminum oxyhydroxide nanopowders}

Physico-chemical features of the NPs are summarized in Table 1. The spherical morphology of the bulk $\gamma$-AlOOH NPs is illustrated in Figure 2. Elementary particles form agglomerates from 1 to $20 \mu \mathrm{m}$. The efficiency of the recovery of the ultrafine fractions after elutriation was verified by a DLS analysis in water: in the ultrafine fraction sample, only particle agglomerates under $800 \mathrm{~nm}$ (cutting threshold of the cyclone) were present. It was established that the ultrafine fraction represented $10 \%$ of the bulk powder, calculated as the mass ratio between the bulk powder introduced $(10 \mathrm{mg})$ and the ultrafine fraction recovered $(1 \mathrm{mg})$. Raw boehmite nanopowder and its ultrafine elutriated fraction showed similar specific surface areas (157 and $163 \mathrm{~m}^{2} / \mathrm{g}$ respectively), unaltered primary NPs diameter (13 and $12 \mathrm{~nm}$ respectively)... Only the hydrodynamic diameter was modified (185 and $1125 \mathrm{~nm}$ for bulk powder versus 80 and $400 \mathrm{~nm}$ for the ultrafine fraction).

$\mathrm{HO} \bullet$ and $\mathrm{COO}^{-}$free radical release assessed by EPR was found to be negative (data not shown) both for the bulk boehmite nanopowder and its ultrafine fraction.

\subsubsection{Study of lab synthesized $\gamma$-AlOOH nanopowders}

Physico-chemical features of the lab synthesized $\gamma$-AlOOH NPs are summarized in Table 1. As observed with SEM (Figure 3A), the dried powder is formed of agglomerates from 1 to $200 \mu \mathrm{m}$ diameter. TEM analyses (Figure 3B) revealed that constitutive NPs (20 to $50 \mathrm{~nm}$ ) were well-faceted and crystallized. After dispersion, only one population was present, showing a $210 \mathrm{~nm}$ hydrodynamic diameter (corresponding to small agglomerates of NPs), compared to the initial highly agglomerated and polydispersed HS particles (hydrodynamic diameter: 218 and $4913 \mathrm{~nm}$ ). 
$\mathrm{No} \mathrm{HO} \bullet$ and $\mathrm{COO}^{-}$free radical release was observed for HS as well as for dispersed HS nanopowders (data not shown).

\subsection{In vitro biological activity}

Figures 4 and 5 report the cytotoxic and pro-inflammatory effects of manufactured and HS $\gamma$ AlOOH NPs respectively.

Concerning industrial NPs, the basal amount of LDH released by cells alone was increased in a dose-dependent manner when cells were incubated with DQ12 quartz (Figure 4A). The LDH release was negligible with $\gamma$-AlOOH NPs whereas it was maximal with the ultrafine fraction (about 12\% and 35\% respectively), whatever the nanoparticle dose. This suggests that, contrary to the raw powder, the ultrafine fraction is highly cytotoxic as shown by a LH release three times higher. A similar conclusion can be reached for the pro-inflammatory effect (Figure 4B) as the TNF $\alpha$ production induced by raw boehmite NPs was negligible compared to that induced by the ultrafine fraction (about $500 \mathrm{pg} / \mathrm{ml}$ and $2000 \mathrm{pg} / \mathrm{ml}$ respectively), irrespective of the nanoparticle dose. The ultrafine fraction was even more proinflammatory than the DQ12 quartz positive control. Taken together these results argue for a size effect of the NPs agglomerates as the ultrafine fractions induced enhanced biological effects compared to raw nanopowders.

Finally, no oxidative stress was observed either for the raw nanopowder or its ultrafine fraction (data not shown).

Concerning the lab synthesized NPs, no significant cytotoxicity was observed both for HS and dispersed HS nanopowders (Figure 5A). As shown by Figure 5B, HS NPs did not induce a pro-inflammatory response (TNF $\alpha$ production not significantly different from that of control cells), contrary to dispersed HS NPs for which the amount of the pro-inflammatory cytokine 
was highly enhanced, even exceeding that induced by DQ12 quartz. Therefore, as previously observed with industrial particles, the agglomeration state seems to represent a key parameter in the biological effect of $\gamma$-AlOOH NPs.

No oxidative stress was observed, as no significant reactive oxygen species was produced when cells were incubated with HS or dispersed HS NPs (data not shown).

To verify the accuracy of the results, TNF $\alpha$ production was expressed depending on the NPs surface area (instead of NP mass dose), as it has been reported that depending on the dosemetric used, results can be misinterpreted (Oberdörster et al. 2005). There are two ways to express surface dose: either depending on the crystallite size using the specific surface area (SSA) or depending on the agglomerate size. SSA is more adequate for dispersed NPs but as this study focuses on the effect of agglomeration it was more pertinent to convert the mass dose into surface dose based on the aggregate size. As illustrated by Figure 6 the proinflammatory activity of the ultrafine fraction of industrial boehmite was much more higher than that of the bulk nanopowder, confirming the biological effect triggered by the former and the nanoparticle agglomerates size-dependent pro-inflammatory effect. Similar results were observed for LDH (data not shown).

Similar conclusion was reached for HS NPs when NPs doses were expressed in surface (Figure 7). This representation confirmed that the pro-inflammatory effect was dependent on the agglomeration state of the NPs. 


\section{DISCUSSION}

The nanotoxicology field was created with the aim to establish the relationship between NPs physico-chemical properties and their toxic potential (Jiang et al. 2009; Oberdörster et al. 2005). The Organisation for Economic Co-operation and Development (OECD) has defined a list of the major physico-chemical characteristics that should systematically be evaluated in any nanotoxicological study (OECD guideline 2008). It includes, among others, the particles shape, size distribution, surface area/chemistry/charge, agglomeration state, chemical composition/impurities...

Very few data are available in the literature concerning the potential toxicity of AlOOH NPs despite a growing use of this material. Moreover, during handling of bulk manufactured NPs powder dust may be released to the workroom air. It is therefore important to take into account the dustiness of nanopowders as it is directly related to the exposure levels and hence to health risks (Schneider and Jensen 2009; Tsai et al. 2009). The size distribution and structure of NPs in the breathing zone of workers will differ from the primary NPs produced. Dustiness testing can provide insight into the state of agglomeration of particles released during handling of bulk nanopowders. These activities can be simulated in dustiness tests, i.e., bench-scale tests using an agitation mechanism supposed to simulate a range of real handling scenarios. Different test methods have been developed: single drop, continuous drop, rotating drum, and fluidization (Schneider and Jensen 2009), underlining the importance to take into consideration the dustiness fraction of manufactured powders.

In the present study, a raw industrial $\gamma-\mathrm{AlOOH}$ powder was studied as well as the ultrafine, respirable, fraction of this powder obtained by elutriation. The above-mentioned physicoparameters were thoroughly characterized and biological assays revealed a major impact of the NPs agglomeration state on the toxicity. Indeed, NPs from the raw nanopowder and its ultrafine fraction presented similar physico-chemical features: specific surface area, primary 
particles size, crystallite size, chemical composition and surface reactivity (none of the samples was able to release free radical, despite the presence of few amount of iron as impurity), only the hydrodynamic diameters differed: they were smaller in the ultrafine fraction which was correlated with an increased biological activity. This observation was confirmed by the study of lab synthesized $\gamma$-AlOOH NPs which characteristics were welldefined and tightly controlled. Whereas the original nanopowder did not trigger a significant biological activity, pro-inflammatory response was highly enhanced when NPs were dispersed. These results are in perfect agreement with that of Pauluhn (2009a; 2009b; 2011) who demonstrated a key role of the agglomeration state of NPs on toxicity. These studies showed in a model of rats that the toxicity of inhaled NPs depended on the size of the agglomerates and not on that of the primary particles.

Oberdörster et al. (2005) have demonstrated that depending on the metric used to express the NPs dose, inaccurate assessments can occur and even misleading conclusions can be reached. NPs dose is often expressed as a mass dose, however, in some cases the surface parameter is much more relevant. This is why, our results were also expressed depending on the NPs surface dose. Our data confirmed that, irrespective of the dosemetric used, increased toxicity was correlated with the smallest size of NPs agglomerates (both for manufactured and laboratory-scale synthesized $\gamma$-AlOOH NPs).

Recently, Schrurs and Lison (2012) emphasized the complexity to compare results from different studies reported in the literature. One of the major reasons lies in the wide variety of the experimental approaches adopted. This can be explained by the huge diversity of nanomaterials, the different available assays, the doses employed by each research team, etc... All these factors put together result in a lack of coherence and structure in the way research is conducted in nanotoxicology. After the review of 38 papers focused on the in vitro cytotoxicity of silica NPs, the authors were unable to draw conclusions and answer six basic 
questions that, according to them, should precede a hazard assessment. The first of these basic questions was: “Are silica NPs more cytotoxic than their larger counterparts?". Indeed, concerns about the toxicity of nanomaterials have been mainly based on the assumption that NPs are more toxic than larger particles. In our study, and for the first time, we answered this basic question in the case of boehmite NPs. We clearly demonstrated that the ultrafine, dispersed fraction of a $\gamma-\mathrm{AlOOH}$ powder is more cytotoxic, and particularly more proinflammatory, than its larger counterparts (the raw powders containing agglomerated NPs).

Moreover, to further underline the importance to study the ultrafine fractions of bulk powders, a recent French decree can be mentioned (decree $n^{\circ}$ 2012-232, February 2012). It has introduced the obligation to declare the quantities and uses of the nanoscale substances produced, distributed or imported in France. This system intends to know better these compounds and their applications, to allow a better tracking and to collect more data on their toxicological properties. This decree is based on the definition of a "nanoscale substance" given by the regulation (EC) No 1907/2006 of the European Parliament and of the Council of 18 December 2006 concerning the Registration, Evaluation, Authorization and Restriction of Chemicals (REACH). This regulation was refined on 18 October 2011 when the EC adopted the following definition of a nanomaterial: "A natural, incidental or manufactured material containing particles, in an unbound state or as an aggregate or as an agglomerate and where, for $50 \%$ or more of the particles in the number size distribution, one or more external dimensions is in the size range $1 \mathrm{~nm}-100 \mathrm{~nm}$. In specific cases and where warranted by concerns for the environment, health, safety or competitiveness the number size distribution threshold of $50 \%$ may be replaced by a threshold between 1 and $50 \%$ ". This definition remains evasive but it clearly stresses the need to take into account the ultrafine fractions. Moreover, as suggested, a 50\% threshold may not be the most relevant ratio for every kind of 
powders. Therefore, it should be interesting to deepen our knowledge of the ultrafine fractions and their biological effects to justify such a choice, based on scientific data.

\section{CONCLUSIONS}

In conclusion, our results clearly indicate that the degree of agglomeration of AlOOH NPs has a major impact on their toxicity. They also highlight the need to study not only raw industrial nanopowders but also to select the ultrafine fractions of these powders to investigate the effects of the fine (or ultrafine) particles which size is representative of the pulmonary retention of inhaled particles. Even if further investigations are needed, this study can provide a basis for a "safer by design" approach. Indeed, avoiding disaggregation of the particles in the manufacturing processes and applications can be a strategy to limit the potential hazard of AlOOH NPs.

\section{DECLARATION OF INTEREST STATEMENT}

This work was supported by the French Ministry of Industry and an industrial partner. 


\section{REFERENCES}

Boczkowski J and Hoet P. 2010. What's new in nanotoxicology? Implications for public health from a brief review of the 2008 literature. Nanotoxicology 4, 1-14.

Bonnefont-Rousselot D, Chantalat-Auger C, Teixeira A, Jaudon MC, Pelletier S, Cherin P. 2004. Blood oxidative stress status in patients with macrophagic myofasciitis. Biomed Pharmacother 58, 516-519.

Bruch J, Rehn S, Rehn B, Borm PJ, Fubini B. 2004. Variation of biological responses to different respirable quartz flours determined by a vector model. Int J Hyg Environ Health 207 (3), 203-16.

Crisponi G, Nurchi VM, Bertolasi V, Remelli M, Faa G. 2012. Chelating agents for human diseases related to aluminum overload. Coord Chem Rev 256, 89-104.

Décret no 2012-232 du 17 février 2012 relatif à la déclaration annuelle des substances à l'état nanoparticulaire pris en application de l'article L. 523-4 du code de l'environnement. Journal Officiel de la République Française.

De la Harpe $\mathbf{J}$ and Nathan CF. 1985. A semi-automated micro-assay for $\mathrm{H}_{2} \mathrm{O}_{2}$ release by human blood monocytes and mouse peritoneal macrophages. J Immunol Methods 78 (2), 323 36.

Fubini B, Mollo L, Giamello E. 1995. Free radical generation at the solid/liquid interface in iron containing minerals. Free Radical Res 23 (6), 593-614.

Fubini B, Ghiazza M, Fenoglio I. 2010. Physico-chemical features of engineered nanoparticles relevant to their toxicity. Nanotoxicology 4 (4), 347-363. 
Jiang J, Oberdörster G, Biswas P. 2009. Characterization of size, surface charge, and agglomeration state of nanoparticle dispersions for toxicological studies. J Nanopart Res 11 , $77-89$.

Kuhlbusch TAJ, Krug HF, Nau K, Krug HF, Kusche O, Dickerhof M, Quendt C, Fleischer T, Mülhopt S, Paur HR. 2009. NanoCare: Health related aspects of nanomaterials: Final scientific report, ed Dechema, Frankfurt.

Leclerc L, Boudard D, Pourchez J, Forest V, Sabido O, Bin V, Palle S, Grosseau P, Bernache D, Cottier M. 2010. Quantification of microsized fluorescent particles phagocytosis to a better knowledge of toxicity mechanisms. Inhal Toxicol 22, 1091-1100.

Magdolenova Z, Bilaničová D, Pojana G, Fjellsbø LM, Hudecova A, Hasplova K, Marcomini A, Dusinska M. 2012. Impact of agglomeration and different dispersions of titanium dioxide nanoparticles on the human related in vitro cytotoxicity and genotoxicity. J Environ Monit 14 (2), 455-64.

Murdock RC, Braydich-Stolle L, Schrand AM, Schlager JJ, Hussain SM. 2008. Characterization of nanomaterial dispersion in solution prior to in vitro exposure using dynamic light scattering technique. Toxicol Sci 101 (2), 239-53.

Noël A, Maghni K, Cloutier Y, Dion C, Wilkinson KJ, Hallé S, Tardif R, Truchon G. 2012. Effects of inhaled nano- $\mathrm{TiO}(2)$ aerosols showing two distinct agglomeration states on rat lungs. Toxicol Lett 214 (2), 109-19.

Oberdörster G, Oberdörster E, Oberdörster J. 2005. Nanotoxicology: an emerging discipline evolving from studies of ultrafine particles. Environ Health Perspect 113 (7), 823-39. 
OECD Environment, Health and Safety Publications Series on the Safety of Manufactured Nanomaterials. ENV/JM/MONO(2008)13/REV.

Pauluhn J. 2009a. Pulmonary toxicity and fate of agglomerated 10 and $40 \mathrm{~nm}$ aluminum oxyhydroxides following 4-week inhalation exposure of rats: toxic effects are determined by agglomerated, not primary particle size. Toxicol Sci 109 (1), 152-167.

Pauluhn J. 2009b. Retrospective analysis of 4-week inhalation studies in rats with focus on fate and pulmonary toxicity of two nanosized aluminum oxyhydroxides (boehmite) and pigment-grade iron oxide (magnetite): The key metric of dose is particle mass and not particle surface area. Toxicology 259, 140-148.

Pauluhn J. 2011. Poorly soluble particulates: Searching for a unifying denominator of nanoparticles and fine particles for DNEL estimation. Toxicology 279, 176-188.

Regulation (EC) No 1907/2006 of the European Parliament and of the Council of 18 December 2006 concerning the Registration, Evaluation, Authorisation and Restriction of Chemicals (REACH). Official Journal of the European Union.

Schneider T and Jensen KA. 2009. Relevance of aerosol dynamics and dustiness for personal exposure to manufactured nanoparticles. J Nanopart Res 11, 1637-1650.

Schrurs F and Lison D. 2012. Focusing the research efforts. Nat Nanotechnol 7 (9), 546-8.

Tsai CJ, Wu CH, Leu ML, Chen SC, Huang CY, Tsai PJ, Ko FH. 2009. Dustiness test of nanopowders using a standard rotating drum with a modified sampling train. J Nanopart Res $11,121-131$ 
Wang W and Singh M. 2011. Selection of adjuvants for enhanced vaccine potency. World J Vaccines 1, 33-78. 


\section{FIGURE CAPTIONS}

Fig. 1 Experimental setting for ultrafine fraction recovery of industrial boehmite

Fig. 2 Morphology of raw $\gamma$-AlOOH nanopowder observed by SEM

Fig. 3 Morphology of HS $\gamma$-AlOOH nanopowder observed by SEM (A) and TEM (B)

Fig. 4 Cytotoxic and pro-inflammatory effects of NPs from a bulk industrial powder and from its ultrafine fraction: $\mathrm{LDH}$ release (A) and TNFa production (B) are reported depending on the NPs dose. A negative control (cells incubated alone) and a positive control (DQ12 quartz) are also reported. Results are means of 3 independent experiments. Significant differences $(\mathrm{p}<0.0001$, ANOVA test $)$ are indicated $(*)$

Fig. 5 Cytotoxic and pro-inflammatory effects of HS and dispersed HS NPs: LDH release (A) and TNF $\alpha$ production (B) are reported depending on the NPs dose. Cells incubated alone and DQ12 quartz were included as negative and positive controls respectively. Results are means of 3 independent experiments. Significant differences ( $p<0.0001$, ANOVA test) are indicated $(*)$

Fig. 6 TNF $\alpha$ production expressed depending on the surface dose of industrial $\gamma$-AlOOH NPs

Fig. 7 TNF $\alpha$ production expressed depending on the surface dose of HS $\gamma$-AlOOH NPs 
Figure 1

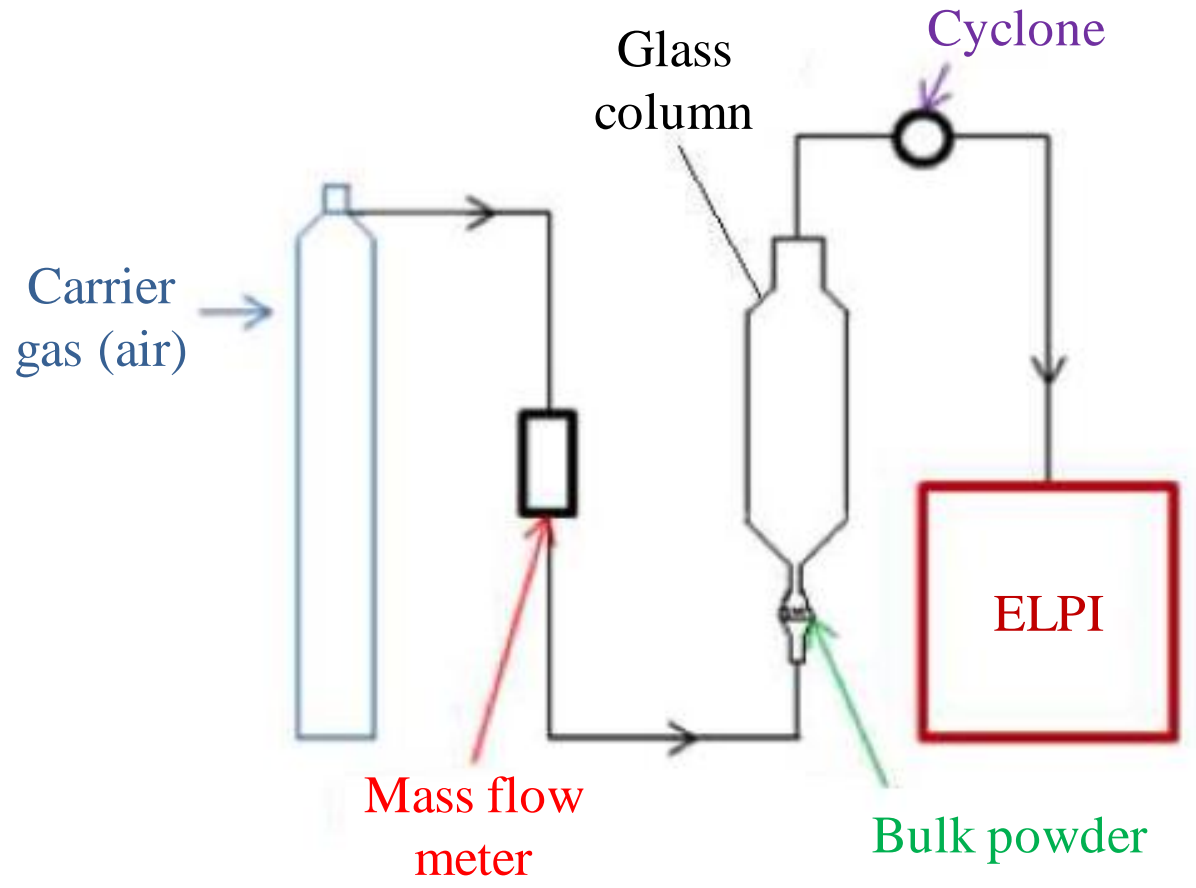


Figure 2

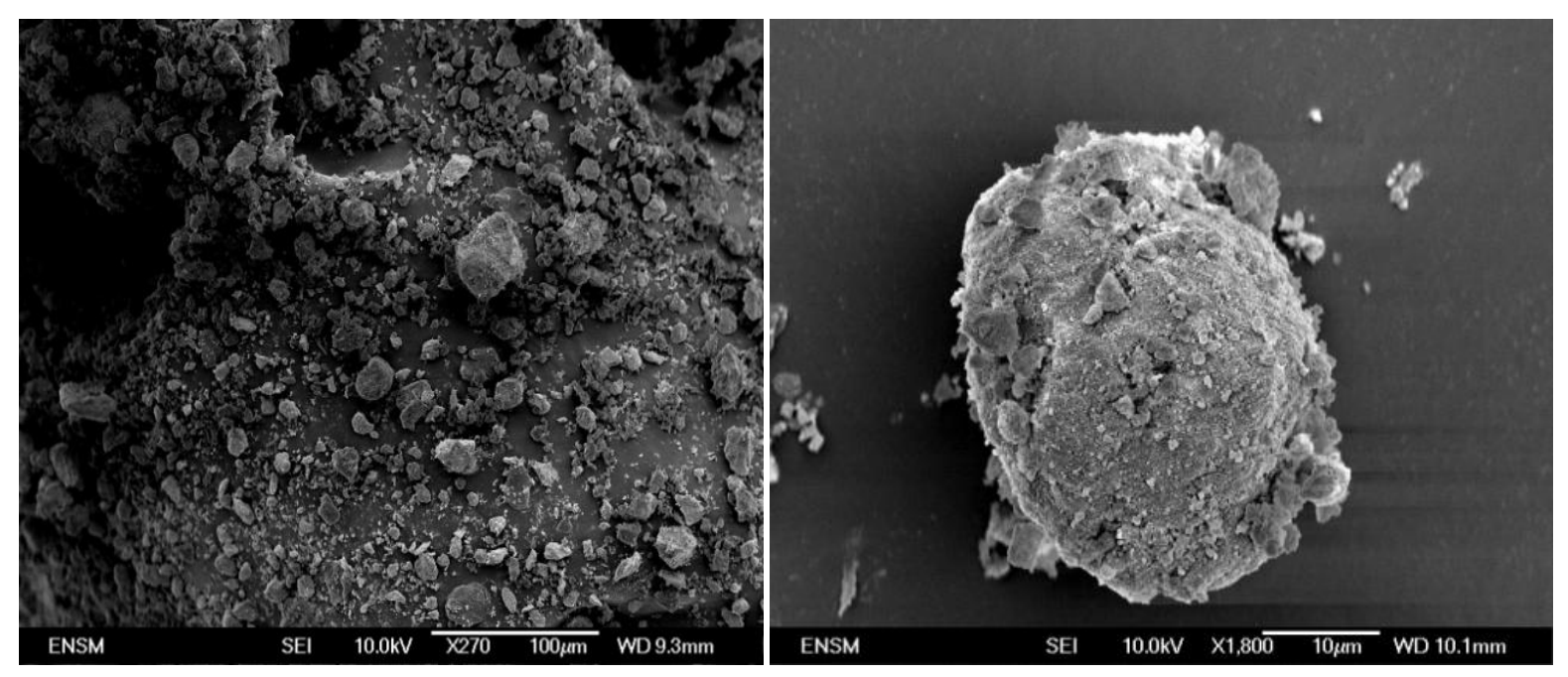


Figure 3

A)

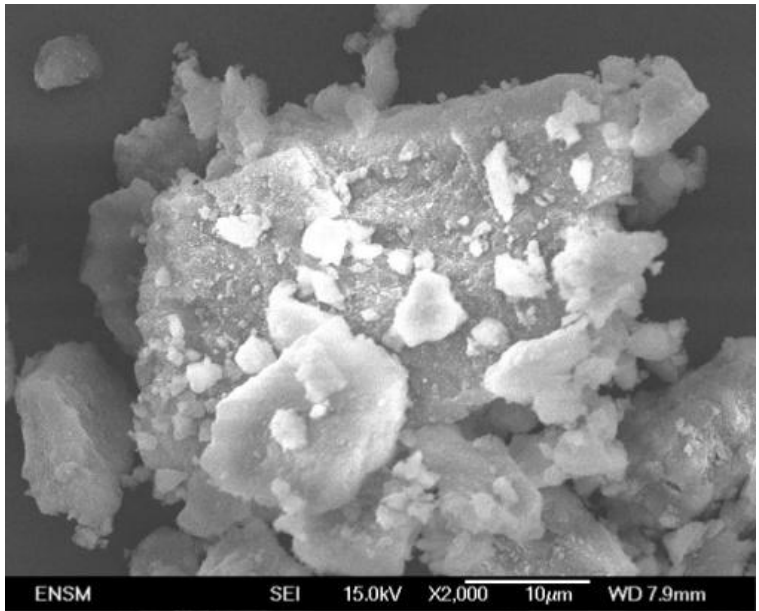

B)

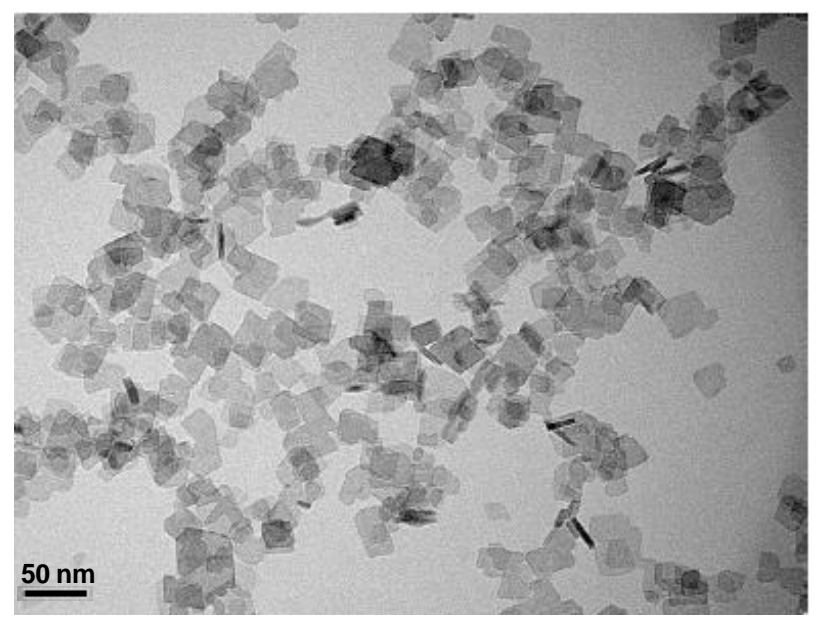


Figure 4

A)

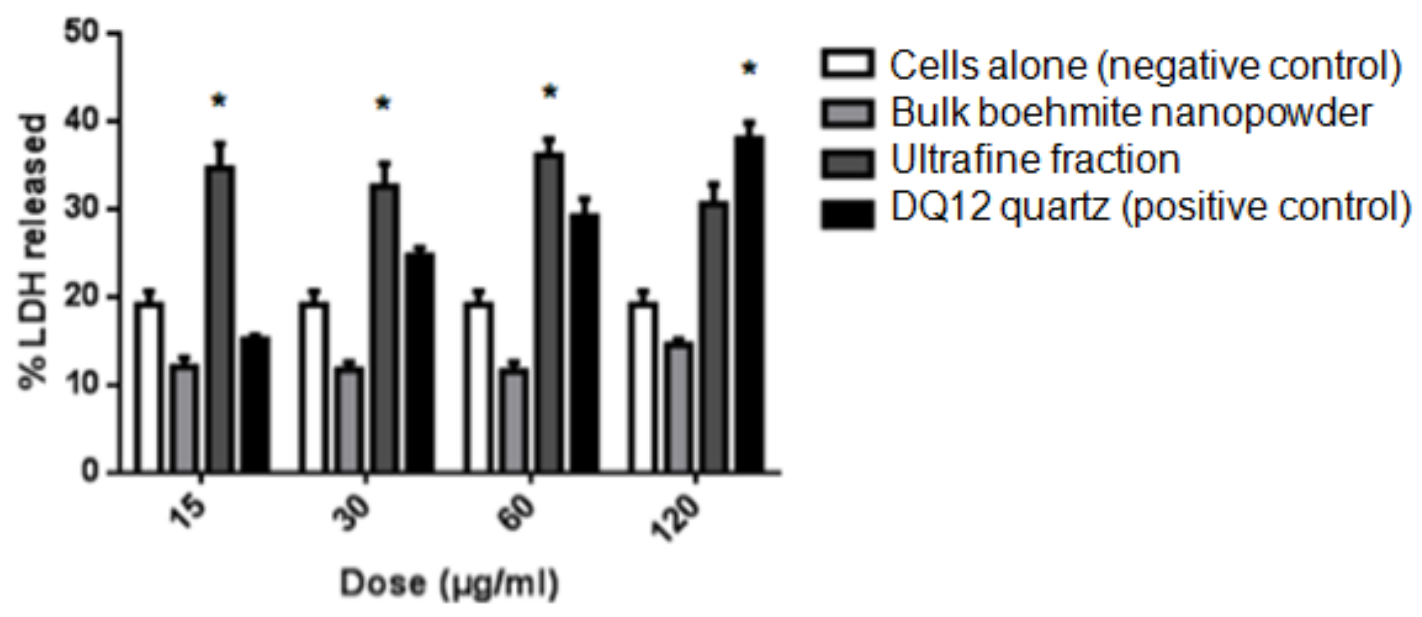

B)

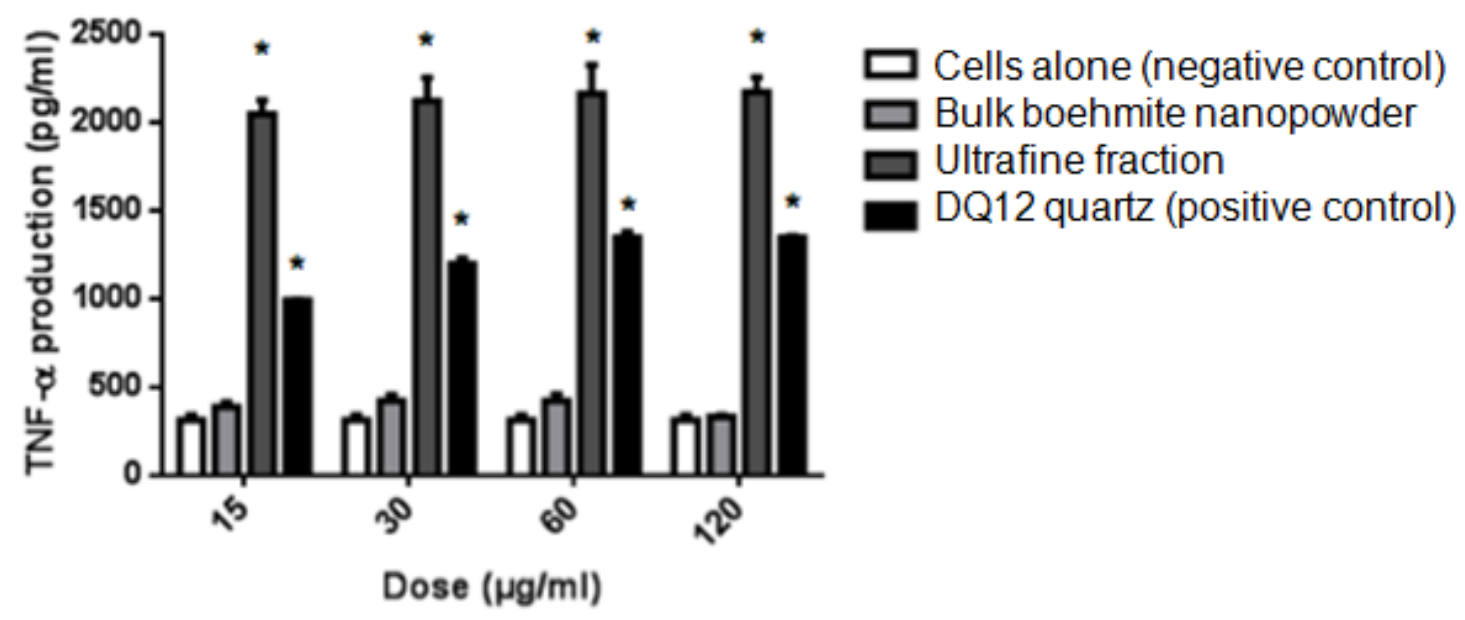


Figure 5

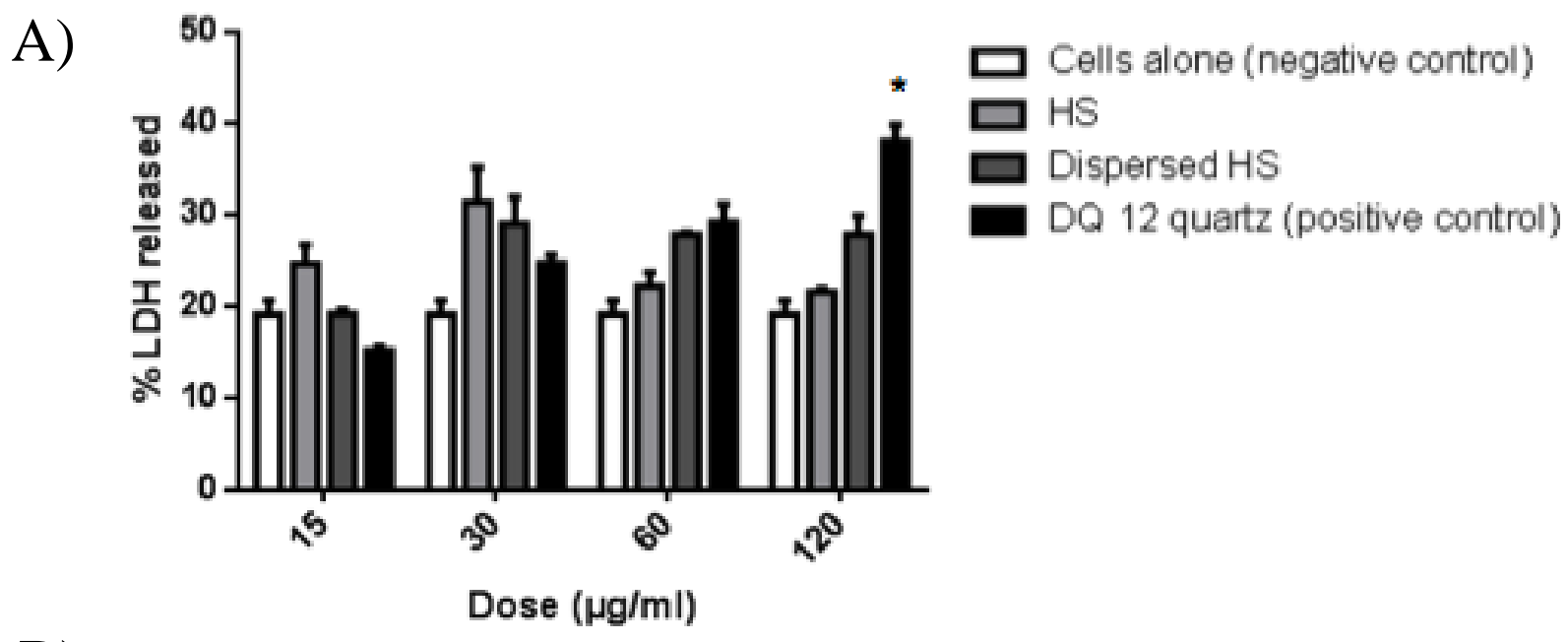

B)

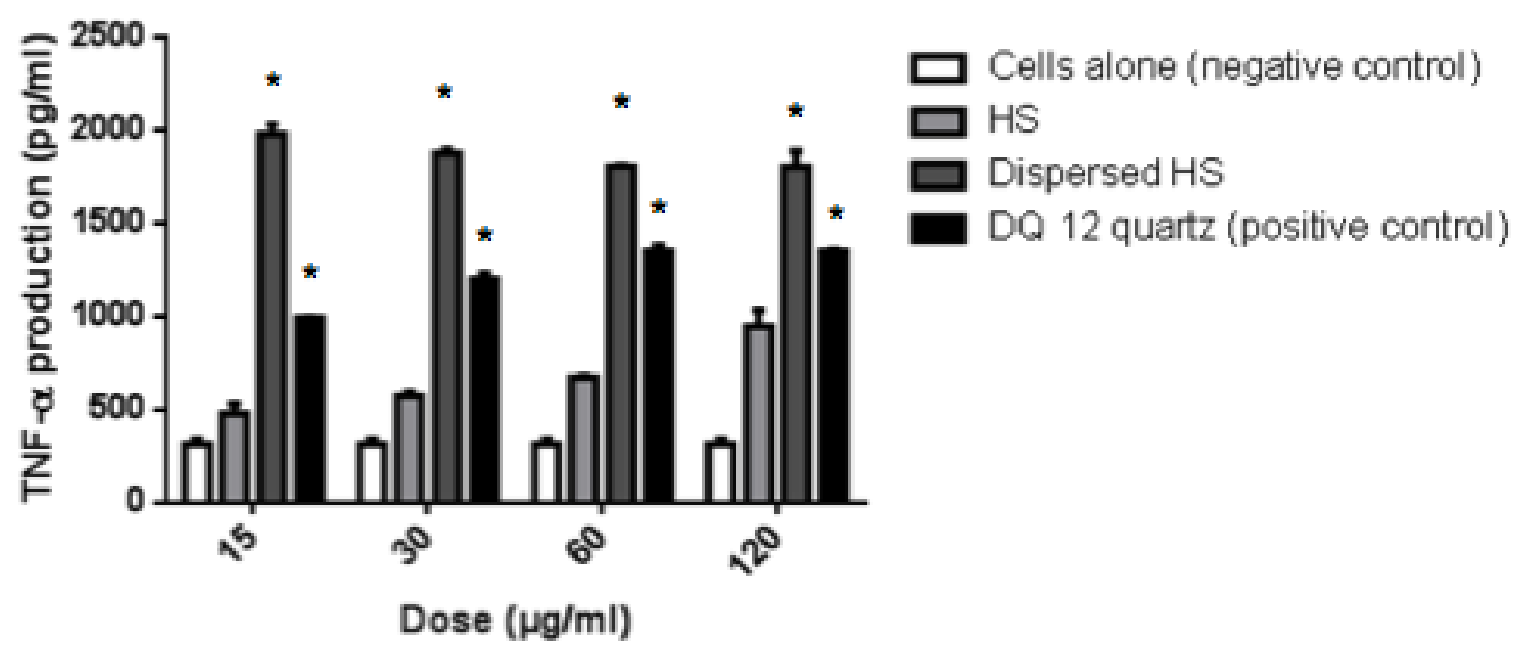


Figure 6

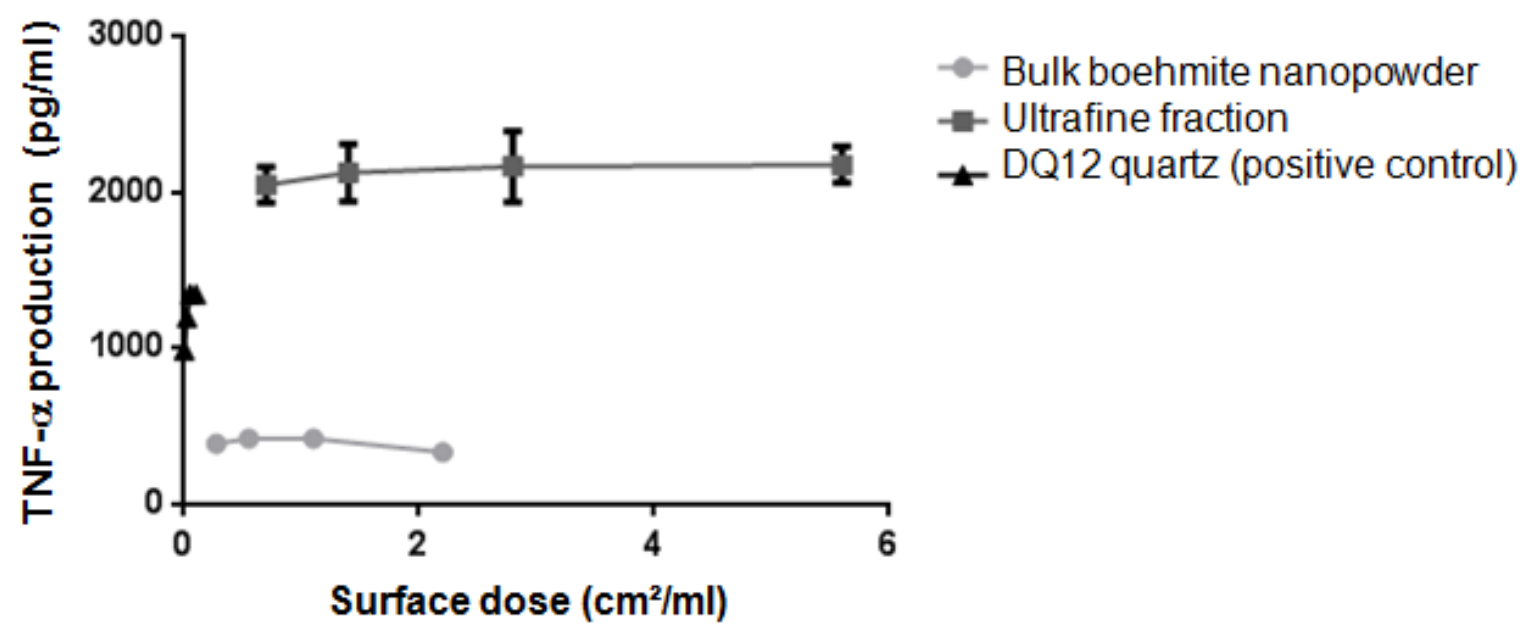


Figure 7

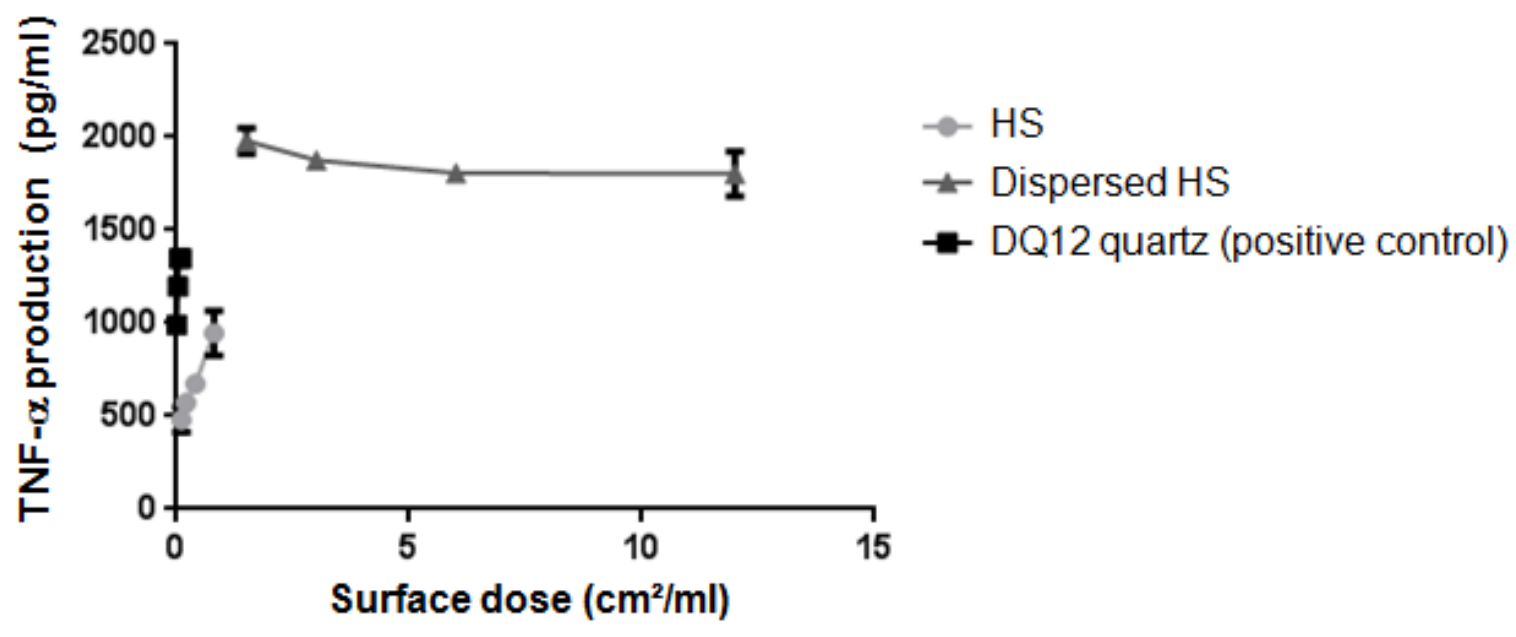


Table 1 - Physico-chemical features of a raw industrial boehmite powder and its ultrafine fraction obtained after elutriation and of the $\gamma$-AlOOH nanoparticles produced by hydrothermal synthesis (HS) at the laboratory scale before and after dispersion. ND: not determined.

\begin{tabular}{|c|c|c|c|c|c|}
\hline & \multicolumn{2}{|c|}{ Industrial boehmite } & \multicolumn{2}{|c|}{ HS } \\
\hline & & Raw powder & Ultrafine fraction & HS & Dispersed HS \\
\hline \multicolumn{2}{|c|}{ Morphology (from SEM) } & Spherical & Spherical & Faceted & Faceted \\
\hline \multicolumn{2}{|c|}{$\begin{array}{c}\text { Hydrodynamic diameter (from DLS): } \\
\text { - in water (and distribution in \% intensity) } \\
\text { - in DMEMc (and distribution in \% intensity) }\end{array}$} & $\begin{array}{c}185 \mathrm{~nm}(30 \%) / 1125 \mathrm{~nm}(70 \%) \\
15 \mathrm{~nm}(20 \%) / 460 \mathrm{~nm}(80 \%)\end{array}$ & $\begin{array}{c}80 \mathrm{~nm}(10 \%) / 400 \mathrm{~nm}(90 \%) \\
\mathrm{ND}\end{array}$ & $\begin{array}{c}218 \mathrm{~nm}(95 \%) / 4913 \mathrm{~nm}(5 \%) \\
\mathrm{ND}\end{array}$ & $\begin{array}{c}110 \mathrm{~nm}(100 \%) \\
\mathrm{ND}\end{array}$ \\
\hline \multicolumn{2}{|c|}{$\begin{array}{c}\text { Median diameter }(\mu \mathrm{m}) \\
\left(D_{50} \text { from laser granulometry) }\right.\end{array}$} & 18 & ND & 42 & ND \\
\hline \multicolumn{2}{|c|}{ Specific Surface Area $\left(\mathrm{m}^{2} / \mathrm{g}\right)$ (from BET) } & 157 & 163 & 132 & ND \\
\hline \multicolumn{2}{|c|}{ Crystallites size (nm) (from XRD) } & 10 & 12 & 14 & ND \\
\hline \multicolumn{2}{|c|}{\begin{tabular}{|l} 
Primary particles diameter $(\mathrm{nm})$ (from TEM) \\
from
\end{tabular}} & 13 & 12 & 15 & ND \\
\hline - in water & $D L S):$ & $\begin{array}{c}35.2 \\
-10.1\end{array}$ & $\begin{array}{l}\text { ND } \\
\text { ND }\end{array}$ & $\begin{array}{c}28 \\
\text { ND }\end{array}$ & $\begin{array}{l}\text { ND } \\
\text { ND }\end{array}$ \\
\hline \multicolumn{2}{|c|}{ Isoelectric point (from $D L S$ ) } & 9.4 & ND & 8.4 & ND \\
\hline \multirow{3}{*}{$\begin{array}{c}\text { Chemical analysis }(\mathrm{ppm}) \\
(\text { from } I C P)\end{array}$} & $\mathrm{Fe}$ & 51 & 41 & 198 & ND \\
\hline & $\mathrm{Si}$ & 81 & 62 & ND & ND \\
\hline & $\mathrm{Na}$ & 206 & 112 & 1590 & ND \\
\hline \multirow{5}{*}{$\begin{array}{c}\text { Surface composition (atom \%) } \\
\text { (from XPS) }\end{array}$} & $\mathrm{O}$ & 56 & ND & ND & ND \\
\hline & $\mathrm{Al}$ & 39 & ND & ND & ND \\
\hline & $\mathrm{Si}$ & 2.5 & ND & ND & ND \\
\hline & $\mathrm{C}$ & 2.5 & ND & ND & ND \\
\hline & $\mathrm{Al} / \mathrm{O}$ ratio & 0.7 & ND & ND & ND \\
\hline
\end{tabular}

